\title{
Prevalence and correlates of asthma among selected garment factory workers at the Free Trade Zone, Ekala
}

\author{
P. Jayawardana ${ }^{1}$, C. Abeysena ${ }^{2 *}$
}

\begin{abstract}
Objective

To determine prevalence of bronchial asthma (BA) and its correlates and respiratory functions among selected garment factory workers (GFW) at the Free Trade Zone, Ekala.

\section{Methods}

This consisted of a cross sectional descriptive and an analytical study. It was conducted at three selected garment factories and a clinic setting in Ekala. Study group for first component included $674 \mathrm{GFW}$ who have worked for 1 or more years at the current garment factories. Control group for second component included 100 participants who have never worked in garment factories. Study instruments consisted of an interviewer administered questionnaire and spirometry. Bivariate analysis was followed by multiple logistic regressions. Results were expressed as odds ratios (OR) and $95 \%$ Confidence intervals (CI).
\end{abstract}

\section{Results}

Overall prevalence of BA among GFW was 32.3\% (95\% CI:28.8-36.0\%). Prevalence of "probable occupational asthma" among asthmatic GFW was 49.5\% (95\% CI:42.7-56.4\%). Being a GFW $(\mathrm{OR}=3.5,95 \% \mathrm{CI}: 1.9-7.2)$ and age $>30$ years $(\mathrm{OR}=1.5 ; 95 \% \mathrm{CI}: 1.1-2.1)$ were significantly associated with prevalence of BA. Among GFW, FEV1.0 and PEFR were significantly lower among asthmatics compared to non asthmatics, and FVC, FEV1.0, and PEFR among those exposed to dust for $>3$ years compared to $\leq 3$ years.

\section{Conclusions}

Prevalence of bronchial asthma was higher among Garment Factory Workers. However, respiratory functions were lower only among those who were asthmatics.

Key words: asthma, occupation, prevalence, risk, respiratory functions

\section{Introduction}

The American Thoracic Society (1) defines asthma as a "chronic inflammatory disorder of the airways that causes recurrent episodes of coughing, wheezing, chest tightness and dyspnoea". Chronic inflammation is said to make "the airways sensitive to stimuli such as allergens, chemical irritants, tobacco smoke, cold air and exercise". Exposure to above leads to oedema, constriction, mucus formation and hyper-responsiveness resulting in variable airways obstruction.

Work related asthma refers to asthma that is induced (occupational asthma) or exacerbated (work exacerbated asthma) by inhalational exposures in the workplace $(2,3)$. Bernstein et al(4) describes occupational asthma as a disease that is "characterized by variable airflow limitation and/or nonspecific airway hyperresponsiveness due to causes and conditions 
attributable to a particular occupational environment and not to stimuli encountered outside the workplace" or simply as asthma caused by exposure to agents at work place (5).

Occurrence of asthma has a genetic predisposition. Environmental factors known to precipitate it $(2,6)$ include airborne dust, gases, vapours and fumes $(5,6)$. triggers include adhesives, lacquer, plastics, epoxy resins, foam and rubber insulation, isocyanates, textile dyes and enzymes in detergents and metals including platinum, chromium, and soldering fumes and minerals (nickel sulphate) [chemical exposures], hair and dander of animals (animal proteins), wood, flour and grain dust, green coffee beans, papaine and pollen (plant sources) and miscellaneous factors such as cold weather, exercise, respiratory infections, stress and tobacco smoke (4). According to a report, $17 \%$ of occupational asthma in the UK between 1989 to 1996 , had been attributed to isocyanate exposure (7), which is used in the manufacture of polyurethane foam, rubbers and surface coatings, inks and adhesives and binders for foundry cores.

In general $9 \%-15 \%$ of adult onset asthma is said to be of occupational origin. Further 25\% of new onset asthma (de novo) is assumed to have an occupational basis (2). In a study conducted in an industrialized area in the UK, the annual incidence of occupational asthma was 42 per million working population. It was more frequently reported among welders $(9 \%)$ and health care professions $(9 \%)$ whereas $<1 \%$ of cases were reported in farmers (8). In a study done in France between 1996-99, 2178 cases of occupational asthma were reported, giving a mean annual rate of 24 per million (9). In a cross sectional study done on adult male tannery workers in Pakistan (10), the prevalence of asthma was reported to be $10.8 \%$ of which $5.3 \%$ was perceived work related asthma. In a British Columbian study done on employees of selected industries, the overall prevalence of physiciandiagnosed asthma was $4.6 \%$, and current asthma $3 \%(11)$.

Work related asthma leads to considerable morbidity in the affected worker with loss of productivity. It in turn is associated with loss of employment and income with a huge cost to the society. In addition it will exert a negative impact on the industry and thus on the economy of the country. Sri Lanka's economy is heavily dependent on export of garments as a major source of foreign income. Further it is probably preventable as avoidance of exposure to the specific agent can lead to its cure. Therefore the objectives of this study was to determine the prevalence and correlates of bronchial asthma and compare the respiratory functions of asthmatics and non asthmatics among selected garment factory workers (GFW) of an industrial zone .

\section{Methods}

The study consisted of two components: cross sectional descriptive study conducted to determine the prevalence of asthma and ventilatory capacity among GFW and the cross sectional analytical study to determine factors associated with asthma. It was conducted at three selected garment factories and in a clinic setting. The study group (SG) for the first component consisted of GFW who have completed $\geq$ I year of service at the current garment factories and were exposed to textile dust and the control group (CG) for the second component consisted of participants who have never worked in garment factories.

The sample size for the prevalence study was computed assuming a prevalence of $20 \%$ among GFW and an absolute precision of $3 \%$ at a significance level of 5\%. Sample size computed was 683 . Final sample size was increased to 720 based on the available number of eligible GFW. The sample size for cross sectional analytical 
study was computed assuming a prevalence of $20 \%$ among GFW and $7 \%$ in the general population, at a significance level of $5 \%$, a power of $80 \%$ and an exposed: unexposed ratio of $4: 1$. Thus the numbers required in SG and CG were 326 and 82 respectively.

The study instruments consisted of an interviewer administered questionnaire to determine socio demographic characteristics and information related to asthma and associated factors. Both groups were subjected to spirometry. The correct method of blowing in to the spirometry was demonstrated by the research assistants trained for the purpose. The research participants were allowed a minimum of three practice blows. Three recordings per person were made once they mastered the technique. The highest of the two readings which has less than a variation of $5 \%$ were taken as the final for the relevant respiratory indicators. It was ensured that the participants were not suffering from any breathing difficulties at the time of spirometry and those who complained were subjected to spirometry, when they were free of any respiratory complaints. The respiratory indicators assessed were Forced Vital Capacity (FVC), Forced Expiratory Volume in the first second of the FVC (FEV1.0), and Peak Expiratory Flow Rate (PEFR).These were compared with predicted normal values derived using the regression formulae (12).

Asthma was defined as either presence of wheeze alone or in combination with shortness of breath and dry cough or presence of shortness of breath and dry cough together in the absence of wheezing during the 12 months preceding the survey. Probable occupational asthma was defined as those whose duration of asthma was less than that of duration of service at the garment factory.

Prevalence of asthma was expressed as percentages with respective $95 \%$ confidence intervals $(95 \% \mathrm{CI})$. Ventilatory capacity was expressed as means and SDs. Bivariate analysis was conducted using chi squared test followed by multiple logistic regression to determine the correlates. The results were expressed as odds ratios and respective $95 \%$ CI. The respiratory functions were compared using two sample t-test or Mann Whitney U test depending on the distribution of data.

\section{Results}

A total of 674 workers among 720 eligible from three garment factories were included and the non participation rate was $6.4 \%(46 / 720)$. A total of 100 controls were included and the response rate was $100 \%$. The number of males among SG and CG were 267 (39.6\%) and 73 (73\%) and the difference in the proportions was statistically significant $(\mathrm{P}<0.001)$. The median age of $\mathrm{SG}$ was 26 (IQR=23-33) years with a range of 18-60 years and the same for CG was $27.5(\mathrm{IQR}=24-33)$ years and 20-60 years respectively with no statistically significant difference $(\mathrm{P}=0.24)$. The highest proportions of SG $(61.4 \% ; n=414)$ and CG $(60 \% ; n=60)$ were between 21-30 years. The proportion in SG (61.3.7\%; $n=413)$ with an educational level of $\geq$ GCE Ordinary Level was significantly lower $(\mathrm{P}<0.001)$ than that in $\mathrm{CG}(97 \% ; \mathrm{n}=97)$.

The proportion in SG who had been previously employed in garment factories was $36.8 \%$ $(n=248)$. The median duration of total service in the garment factories was $4(\mathrm{IQR}=2-8)$ year, with a range of 1-24 years. The highest proportion $(13.4 \% ; n=90)$ had a service of 2 years. The median service duration in the current job was 3 $(\mathrm{IQR}=2-7)$ years with a range of 1-24 years. For the $\mathrm{CG}$ it was 2 (IQR=1-6) years with a range of 1-17 years. The proportion in SG who worked in dusty areas of the factory was $97 \%(n=654)$. Among them the proportion of workers who were exposed to dust for $>3$ years at the current work place was $65.9 \%(\mathrm{n}=431)$. 
Table 1 Unadjusted odds ratios for bronchial asthma by selected socio-demographic and lifestyle variables among garment factory workers (GFW)

\begin{tabular}{|c|c|c|c|c|c|}
\hline \multirow[t]{2}{*}{ Variable } & \multicolumn{3}{|c|}{ Presence of Bronchial Asthma } & \multirow{2}{*}{$\begin{array}{c}\text { Odds Ratio } \\
95 \% \text { CI }\end{array}$} & \multirow[t]{2}{*}{ p value } \\
\hline & & Yes & No & & \\
\hline Group & $\mathrm{FGW}(\mathrm{n}=674)$ & $218(94.6 \%)$ & $456(84 \%)$ & 3.2 & $<0.001$ \\
\hline $\mathrm{N}=774$ & Control $(\mathrm{n}=100)$ & $13(5.6 \%)$ & $87(16 \%)$ & $1.8-5.9$ & \\
\hline Sex & Male $(n=340)$ & $76(33 \%)$ & $264(49)$ & 0.52 & $<0.001$ \\
\hline $\mathrm{N}=774$ & Female $(\mathrm{n}=434)$ & $155(67 \%)$ & $279(51 \%)$ & $0.4-0.7$ & \\
\hline Age & $>30$ years $(n=243)$ & $90(39 \%)$ & $153(28 \%)$ & 1.6 & 0.003 \\
\hline $\mathrm{N}=774$ & $\geq 30$ years $(\mathrm{n}=531)$ & $141(61 \%)$ & $390(72 \%)$ & $1.2-2.3$ & \\
\hline Educational Level & $\leq$ Gr. $10(n=264)$ & $101(44 \%)$ & $163(30 \%)$ & 1.8 & $<0.001$ \\
\hline $\mathrm{N}=774$ & $>$ Gr. $10(\mathrm{n}=510)$ & $130(56 \%)$ & $380(70 \%)$ & $1.3-2.5$ & \\
\hline Current Smoking & Yes $(n=109)$ & $20(09 \%)$ & $89(17 \%)$ & 0.45 & 0.004 \\
\hline $\mathrm{N}=761^{*}$ & No $(n=652)$ & $208(91 \%)$ & $444(83 \%)$ & $0.3-0.8$ & \\
\hline Raring Pets & Yes $(n=308)$ & $80(35 \%)$ & $228(42 \%)$ & 0.7 & 0.05 \\
\hline $\mathrm{N}=769 *$ & No $(n=461)$ & $150(65 \%)$ & $311(58 \%)$ & $0.53-1.01$ & \\
\hline
\end{tabular}

* Missing data - non response to individual questions

Table 2 Adjusted odds ratios for prevalence of bronchial asthma

\begin{tabular}{lccccc}
\hline Variable & $\boldsymbol{\beta}$ & $\mathbf{S E}$ & Odds Ratio & $\mathbf{9 5 \%}$ CI & p value \\
\hline Group GFW & 1.01 & 0.32 & 2.7 & $1.4-5.0$ & 0.002 \\
Age $>30$ years & 0.42 & 0.17 & 1.5 & $1.1-2.1$ & 0.02 \\
Education $\leq$ Grade 10 & 0.32 & 0.17 & 1.4 & $1.0-2.0$ & 0.06 \\
Current smokers & -0.63 & 0.27 & 0.5 & $0.3-0.9$ & 0.02 \\
\hline
\end{tabular}

$\beta$ - regression coefficient; SE - standard error; $\mathrm{CI}$ - confidence interval 


\section{Prevalence of asthma among GFW}

The total number with BA in SG was 218 giving an overall prevalence of $32.3 \%$ (95\% CI: $28.8 \%-36.0 \%$ ). Prevalence among CG was $13 \%$ (95\% CI:6.4\% to $20.0 \%$ ) and the difference was statistically significant with an OR of $3.2(95 \%$ CI:1.7-5.8).

The prevalence of "probable occupational asthma" among asthmatic GFW as defined [108/218] was 49.5\% (95\% CI: 42.7\%-56.4\%) and the proportion with "physician diagnosed" BA was $31.7 \%$, (69/218).

\section{Correlates of asthma}

Except "pets at home" all the other variables tested were significantly associated with prevalence of BA among both groups (Table 1). According to the multivariate analysis, being a GFW and age $>30$ years were the variables that remained significantly associated with BA (Table 2) whereas smoking was found to be a protective factor.

\section{Respiratory function among those with and without asthma among GFW}

The mean values of the three respiratory indicators (RI) were higher among non asthmatics in comparison to asthmatics. The differences of FEV1.0 $(\mathrm{P}<0.001)$ and PEFR $(\mathrm{P}<0.001)$ values were statistically significant (Table 3 ). All three RI had significantly lower mean values among those exposed to dust $(\mathrm{P}<0.01)$ for $>3$ years compared to $\leq 3$ years (Table 4 ). When comparing differences between observed and predicted measurements of the three RIs PEFR of, asthmatics demonstrated significantly lower values (Table 5).

\section{Discussion}

According to the findings of the study the overall prevalence of asthma among GFW was $32.3 \%$. They were at a higher risk of suffering from asthma in comparison to CG with an OR of 3.5.
Prevalence of "probable occupational asthma" in this was $16 \%$ and it accounted for nearly $50 \%$ of all cases of BA among GFW.

Reported proportion of BA due to occupational exposure varies from $5 \%$ to $>30 \%$ in the USA and Europe (6). It is accounted to over $25 \%$ among the new cases recorded each year as reported by the SWORD project (13) in the UK. According to Taylor (14), 1-15\% of BA in the population is attributed to occupational causes. A study in Turkey reported that the prevalence of occupational asthma among denim bleachery workers was $23.8 \%$ (15). However, reported figures vary according to the definitions used and exposures studied. Hence an attempt to compare incidence/prevalence across countries is considered a futile exercise.

Presence of occupational asthma was based on the time of onset of asthma in relation to current employment as a GFW. However, as the diagnosis was based purely on presence of symptoms without objective testing such as work related changes in spirometry and specific inhalational challengers, confirmation of diagnosis of occupational asthma is not possible (2). Therefore, it is speculated that, what is reported in this study could be an overestimate and a certain proportion of them may well be false positives. Also a proportion of cases who developed asthma (as defined) after employment as a GFW may well be related to other sensitizers and not particularly to work exposures. Hence the term "probable occupational asthma" to refer to this group.

With regard to respiratory function, it was observed that all three respiratory indicators of those exposed to dust for $>3$ years was lower than that of those exposed $\geq 3$ years which indirectly indicates the hazarduous nature of textile dust. It has not been reported as an asthmagen in the literature, even though it is well accepted as a causative agent for byssinosis, a respiratory 
Table 3 Comparison of respiratory function of asthmatics and non asthmatics among garment factory workers

\begin{tabular}{lcccc}
\hline Variable & \multicolumn{2}{c}{ Asthma Status } & t value & p value \\
& $\begin{array}{c}\text { Asthmatics } \\
(\mathbf{n = 2 1 8})\end{array}$ & $\begin{array}{c}\text { Non Asthmatics } \\
\text { Mean (SD) }\end{array}$ & $\begin{array}{c}(\mathbf{n = 4 5 5 ) *} \\
\text { Mean (SD) }\end{array}$ & \\
\hline FVC (L) & $2.22(0.99)$ & $2.34(0.68)$ & 1.70 & 0.09 \\
FEV1.0 (L) & $2.14(0.66)$ & $2.32(0.64)$ & 3.33 & 0.001 \\
PEFR (L/sec)** & $5.85(1.46)$ & $6.92(1.52)$ & 5.00 & $<0.001$ \\
\hline
\end{tabular}

* Missing data: $\mathrm{n}=1$ (not participated in spirometry); **Geometric mean

Table 4 Comparison of respiratory function between garment factory workers, working in a dusty environment for a duration of $>3$ years and $\leq 3$ years

\begin{tabular}{lcccc}
\hline Variable & \multicolumn{2}{c}{$\begin{array}{c}\text { Exposure to Dust }(\mathbf{n}=654) \\
\text { >3 years }(\mathbf{n}=431)\end{array}$} & t value & p value \\
& Mean $(\mathrm{SD})$ & Mears $(\mathbf{n = 2 2 3})$ & & \\
\hline FVC $(\mathrm{L})$ & $2.19(0.78)$ & $2.48(0.79)$ & 4.47 & $<0.001$ \\
FEV1.0 $(\mathrm{L})$ & $2.16(0.63)$ & $2.44(0.66)$ & 5.35 & $<0.001$ \\
PEFR $(\mathrm{L} / \mathrm{sec})^{*}$ & $6.14(1.52)$ & $7.35(1.46)$ & 5.56 & $<0.001$ \\
\hline
\end{tabular}

${ }^{\star}$ Geometric mean

Table 5 Comparison of difference of observed and predicted values of respiratory functions among asthmatic and non asthmatic garment factory workers

\begin{tabular}{lccc}
\hline & \multicolumn{3}{c}{ Difference in Observed and Predicted Mean/ Median } \\
& FVC (L) & FEV 1.0 (L) & PEFR (1/s) \\
& Mean (SD) & Mean (SD) & Median (IQR) \\
\hline Asthmatics (n=218) & $0.54(0.82)$ & $0.32(0.46)$ & $1.20(2.24)$ \\
Non Asthmatics (n=455)* & $0.58(0.53)$ & $0.27(0.47)$ & $0.57(2.51)$ \\
P value & 0.49 & 0.22 & $<0.001$ \\
Significance test & t-test & t-test & Mann Whitney U \\
\hline
\end{tabular}

a. *Missing data: $\mathrm{n}=1$ (not participated in spirometry) 
condition that presents with chest tightness, cough and wheeze, but without the classical features of asthma and hence referred to as "asthma like disorder". Byssinosis is a condition known to be associated with specific plant dusts such as cotton, hemp and flax (1).

The ideal therefore, would be total prevention of exposure of GFWs to textile dust. This may be achieved through extraction of dust from the point of origin itself, through which the contact between the offending agent and the workers is completely cut off. Substitution with less asthmagenic textile material is another alternative, which is not probably practical in relation to the garment industry.

Identification of the potential causative agents is another important measure, because the agents incriminated in the development of immunologic and non immunologic occupational asthma are not the same and the management of the two types of occupational asthma differ. Immunologic occupational asthma is mainly due to exposure to high molecular weight agents which consist of plant and animal proteins (2). With regard to garment industry too what is relevant will be the high molecular weight substances. Total removal of the worker from exposure is considered the most suitable measure for immunologic occupational asthma. However, in order to minimize the economic and social impact of this measure on the affected worker, relocation of workers with appropriate alternative vocational training and systems to claim for compensation should be set in place (16).

American Thoracic Society has recommended the need to establish "permissible concentrations" of asthmagens: levels at which immunologic sensitization would not occur (16). However, it cannot be considered a practical measure in Sri Lanka due to the associated costs and the need for trained personnel.

Use of personal protective will be the other available option, but it's ability to protect the worker with zero exposure to dust is hard to achieve. Further, the degree of effectiveness will depend on the compliance of the worker as well as the efficiency of the masks/respirators used for the purpose (16). However, regular use of personal protective equipment was shown to have a protective effect among non-atopic asthmatics, and use of gloves and respiratory protectors among atopic asthmatics in the study among dental healthcare workers (17).

When comparing asthmatics and non asthmatics, the significant difference of median PEFR of observed and predicted values confirms the persistence of airway narrowing in asthmatics even when symptomless. In addition, FEV1.0 and PEFR values of asthmatics were found to be significantly lower than non asthmatic GFW. The study among auto and furniture dye workers in Elazig (18) too had confirmed lower PEFR levels which demonstrated daily variability. Spirometric testing among GFW was done when they were free of any overt respiratory dysfunction and above finding probably is a reflection of the chronic inflammatory process that is a characteristic of bronchial asthma.

Lower level of education (1-8 years of schooling) with an OR of 7.1 was reported to be associated with occupational asthma in the Brazilian study (19) and illiteracy $(\mathrm{OR}=2.1)$ in the Pakistani study.10 In the present study even though low level of education emerged significant in the bivariate analysis, it did not remain same when adjusted for confounding factors.

In a study done on animal shelter workers (20) occupationally exposed to cats and dogs, for whom the prevalence of occupational asthma was $9.1 \%$, As quoted in the article "American Thoracic Society Workshop",18 sensitization to pets had been a risk factor for occupational asthma from exposure to laboratory animals, whereas presence of atopy was not. However, in 
the present study having pets did not emerge as significant even in the bivariate analysis.

Smoking is thought to sensitize people to certain asthmagens (platinum salts) (16), as well as acceleration of decline in lung functions. However, smoking emerged to have a protective effect on BA even after controlling for confounding factors in this study. In the British Columbian study (11) too smoking was observed to be associated with a significant reduction in the risk for BA which developed after employment in the current industry. On the contrary, in the study done on tannery workers in Pakistan (10), ever-smokers were found to have a significant association with occupational asthma. The observed protective effect of smoking in the present study may be attributed to the study design. This being a cross sectional study, what was assessed were current status of both exposure and outcome, and thus lacks the capacity to assess the temporal association to determine which preceded which. This is a recognized limitation of cross sectional studies. It is plausible that most asthmatics were forced to give up smoking after the onset of asthma due to exacerbation of symptoms, leading to a low prevalence of smoking among asthmatics which makes it appear as a protective factor. The Pakistan study (10) which also used a cross sectional study design to assess the association between ever smoking status and occupational asthma, found a significant between sever smoking and BA, However, what was assessed in the present study was the current status of smoking and the interpretation therefore differs. The reported association with ever smoking status probably indicates the additional risk imposed by smoking at any given time including past exposure, on the development of occupational asthma.

Atopy was reported to be significantly associated with occupational asthma in the British Columbian study (11), the Brazilian study (19) and the studies on animal shelter workers (20) and dental health care workers. 17 In the British Columbian study family history was observed to be a risk factor for BA both before and after employment in the current industry (11). However, according to Ameille et al (9) role of genetics lacks consistency in being reported as a significant factor. Both atopy and family history were omitted from the present study due to oversight which limits comparison of these two variables. However, not all studies have reported atopy to be associated with occupational asthma and only one study had described family history to be associated with it. Atopy and family history are unlikely to play a role in the development of non immunological occupational asthma which may explain the inconsistency of the findings observed. $(2,3,4)$ Despite above, one of the limitations in this study is the non inclusion (due to printing errors) of a history of atopy and a family history of asthma. Thus their role as associated factors cannot be discussed in relation to this study, which is considered a limitation.

Among all asthmatics detected by the present study, less than one third (31.7\%) were physician diagnosed cases. One of the reasons for the low trend observed in seeking medical advice may be attributed to lack of awareness of the potential capacity of textile dust to cause work related asthma among the GFWs as well as the management. Since early detection and initiation of treatment has an impact on the prognosis of the disease, awareness on the disease is an important aspect in the management of work related asthma. Regular periodic medical checkups will help early detection of these cases. Institution of early treatment will help control the acute episodes and prevention of relapses and progression of the disease.

It is equally important that the physicians too pay adequate attention in identifying work related asthma, the basic of which is taking a detailed occupational history during the first encounter with the patient. Knowledge on work 
place exposures would go a long way especially in the long term management of these cases, if it entails permanent removal of the patient from the hazardous environment. Even in USA, medical history of work related asthma has been documented only in $15 \%$ of records maintained by general practitioners and only $50 \%$ of referred patients were addressed in terms of work related asthma symptoms (16) by allergists and chest physicians. Thus there is a strong need to enhance the awareness among doctors regarding work related asthma.

Secondary prevention depends on identification of host factors and is anchored on pre employment medical assessment and periodic medical surveillance of the workers using different tools such as questionnaires, spirometry and skin testing to detect atopy. However, use of atopy as a marker has been criticized as an inefficient approach, because not all cases of occupational asthma are due to immunologic occupational asthma and also because 30 to $40 \%$ of young adults in industrialized countries are said to be "atopic" thus reducing the pool of potential new employees (16) Previous history of BA is not considered to be a good predictor of occupational asthma, despite a history of exposure to high molecular weight substances. 16 In such instances use of spirometric assessments have been suggested to identify those at risk. In our opinion those with an existing history of BA should not be considered for employment. However, those with a previous disease history, but free of it currently should not be excluded from employment. However, the need for close monitoring is emphasized in such GFW.

\section{Conclusion}

The GFW were observed to have a prevalence of $32 \%$ for bronchial asthma and $16 \%$ for "probable occupational asthma" which accounts to $50 \%$ of all asthmatics. The only risk factor was age of more than 30 years. Recommend pre employment screening for presence of bronchial asthma, in order that known asthmatics are allocated to tasks that are carried out in less dusty environments. Efficient exhaust ventilation systems should be installed with regular maintenance in the dusty work areas. The results reported had not considered the role of atopy and genetics in the determination of prevalence of bronchial asthma which needs to be assessed in future research.

\section{Conflicts of interest}

None declared

\section{References}

1. American Thoracic Society Documents. American Thoracic Society Statement: Occupational contribution to the burden of airways disease. Am J Respir Crit Care Med 2003; 167: 787-797.

2. Dykewicz MS. Occupational asthma: current concepts in pathogenesis, diagnosis and management. J Allergy Clin Immunol 2009; 123:519-28.

3. Vanenplas $\mathrm{O}$, Malo J-L. Definitions and types of work-related asthma: a nosological approach. Eur Repsir J 2003; 21:706 -12.

4. Chan-Yeung M, Malo J-L Aetiological agents in occupational asthma. Eur Respir J 1994;7: 346 - 347.

5. Busse et al. Expert Panel Report 3 (EPR 3): Guidelines for the Diagnosis and Management of Asthma Summary Report 2007.. J Allergy Clin Immunol 2007; 120 (6): S98.

6. Le Moual N, Kennedy SM, Kauffmann F. Occupational exposures and asthma in 14,000 adults form the general population. 
Am. J Epidemiology 2004:160 (11);1108 1116.

7. Meredith SK, Bugler J, Clark R. Isocyanate exposure and occupational asthma: a case referent study. Occup Environ Med. 2000; 57: 830-836.

8. Bakerly ND, Moore VC, Vellore AD, Jaakkola MS, Robertson AS, Burge PS. Fifteen-year trends in occupational asthma: data from the Shield surveillance scheme. BMJ. 1995:311; 602-603.15

9. Ameille J, Pauli G, Calastreng-Crinquand A, Vervloët D, Iwatsubo Y, Popin E et al. Reported incidence of occupational asthma in France, 1996-99: the ONAP programme. Occupational Medicine 2008;58(3): 19069-174.17

10. Khurram Shahzad, Saeed Akhtar, Sadia Mahmud. Prevalence and determinants of asthma in adult male leather tannery workers in Karachi, Pakistan: A cross sectional study. BMC Public Health 2006, 6:292 doi:10.1186/1471-2458-6292 (Accessed Aug 2009).18, 19

11. Siracusa A, Kennedy SM, DyBuncio A, Lin FJ, Marabini A, Chan-Yeung M. Prevalence and predictors of asthma in working groups in British Columbia. Tuberk Toraks. 2005;53(4):371-8.

12. Udupihilla M. Respiratory function tests: reference norm for the Sinhalese. Ceylon Medical Journal 1995, 40: 53 - 58.

13. Meredith S. Reported incidence of occupational asthma in the United Kingdom, 1989- 90. Occupational and Environmental Medicine. 2003; 60: 136141.13
14. Taylor AJN. Occupational asthma. Postgraduate Medical Journal 1988; 64: 505.510 .

15. Tutar N, Demir R, Büyükoğlan H, Oymak FS, Gülmez I, Kanbay A. The prevalence of occupational asthma among denim bleachery workers in Kayseri. Tüberküloz ve Toraks Dergisi 2011; 59(3): 227-235

16. American Thoracic Society Workshop. American Journal of Respiratory and Critical Care Medicine 2003: 167: 450-471. doi: 10.1164/rccm.167.3.450 (Accessed Aug 2006)

17. Singh T, Bello B, Jeebhay MF. Risk factors associated with asthma phenotypes in dental healthcare workers. Am J Ind Med. 2012 Apr 2. doi: 10.1002/ajim. 22041 (Accessed Aug 2006).

18. Turgut T, Taşdemir C, Muz MH, Deveci F, Kirkil G. The prevalence of occupational asthma in auto and furniture dye workers in downtown Elazig. Curr Opin Pulm Med. 2004:10(2):147-50.

19. Caldeira RD, Bettiol H, Barbieri MA, Terra-Filho J, Garcia CA, Vianna EO. Prevalence and risk factors for work related asthma in young adults. Occup Environ Med 2006; 63:694-699. doi: 10.1136/oem.2005.025916 (Accessed Aug 2009). 17 19,18

20. Krakowiak A, Krawczyk P, Szulc B, Wiszniewska M, Kowalczyk M, Walusiak J, Pałczyński C. Prevalence and host determinants of occupational bronchial asthma in animal shelter workers. $J$. Asthma 2010:47(2):156-61. 